Article

\title{
Fibrin Facilitates Mesenchymal Stem Cells to Ameliorate Rats with Polycystic Ovary Syndrome
}

\author{
Yuanyuan Li ${ }^{1,2,3,+} \mathbb{D}^{\text {, Jia Guo }}{ }^{1,2,3,+}$, Shoulong Deng ${ }^{4,5,+}$, Zili Gao ${ }^{1,2,3}$, Yixun Liu ${ }^{2,6, *}$ \\ and Qi Gu 1,2,3,*(D) \\ 1 State Key Laboratory of Membrane Biology, Institute of Zoology, Chinese Academy of Sciences, \\ Beijing 100101, China; liyuanyuan@ioz.ac.cn (Y.L.); guojia@ioz.ac.cn (J.G.); gaozili18@mails.ucas.ac.cn (Z.G.) \\ 2 Institute of Zoology, University of Chinese Academy of Sciences, Beijing 100049, China \\ 3 Institute for Stem Cell and Regeneration, Chinese Academy of Sciences, Beijing 100101, China \\ 4 Beijing Institute of Genomics, Chinese Academy of Sciences, Beijing 100101, China; dengsl@big.ac.cn \\ 5 Institute of Laboratory Animal Sciences, Chinese Academy of Medical Sciences and Comparative Medicine \\ Center, Peking Union Medical College, Beijing 100021, China \\ 6 State Key Laboratory of Stem Cell and Reproductive Biology, Institute of Zoology, \\ Chinese Academy of Sciences, Beijing 100101, China \\ * $\quad$ Correspondence: liuyx@ioz.ac.cn (Y.L.); qgu@ioz.ac.cn (Q.G.) \\ + These authors contributed equally to this work.
}

Received: 20 April 2020; Accepted: 14 May 2020; Published: 22 May 2020

check for updates

\begin{abstract}
Polycystic ovarian syndrome (PCOS) is a ubiquitous hormonal disorder and induces female infertility and heterogeneous syndromes, for which there is still no effective treatment. Thanks to the properties of immunomodulatory and endocrine regulation, mesenchymal stem cells (MSCs) have been widely used in various disease types. There were few reports for MSCs injected to ovaries due to the size limitation and complicated vascular network. Here, we develop one simple and efficient approach to deliver and stabilize MSCs in the outside of the ovary without blood leaking through the fibrin gelation, which also possesses excellent biocompatibility to support MSC survival. Notably, the transplantation of MSCs, encapsulated in fibrin hydrogel, could rescue ovarian function more efficiently compared to only MSC control in terms of elevated estradiol (E2) and progesterone (P) levels, diminished gonadotropins ( $\mathrm{LH} / \mathrm{FSH})$, testosterone $(\mathrm{T})$, and transforming growth factor- $\beta 1$ (TGF- $\beta 1$ ) levels, regular estrous cycles, enhanced number of granulosa cells, and reduced number of immature cystic follicles. The size and weight of the ovary increased for MSCs both within and without fibrin in PCOS rat models in two weeks. Moreover, we have shown the versatility of fibrin hydrogel as a cell-compatible platform for advanced stem cell translation, including identifying novel mechanisms of cell survival support, tissue development, and regenerative medicine.
\end{abstract}

Keywords: PCOS; MSCs; fibrin; ovarian structure; TGF- $\beta 1$

\section{Introduction}

Polycystic ovarian syndrome (PCOS) is a complicated endocrine disease occurring in 6-7\% of reproductive-age women [1], which affects patients' health by increasing the risk of cardiac disease, obesity, insulin resistance, and infertility [2]. The pathogenesis of PCOS has not been well elucidated, although it has been reported to be a multifactorial disease that involves genetic and environmental factors $[1,3,4]$. Excessive gonadotropin (LH/FSH) and androgen (T) levels affect ovarian function along with increasing transforming growth factor- $\beta 1$ (TGF- $\beta 1$ ) levels and enhancing apoptosis of granulosa cells, in which case, many immature cystic follicles form in the ovaries of PCOS patients [5-7]. Currently, different kinds of therapies are used for the treatment of PCOS such as weight management, medicines targeting insulin resistance, or hormonal drugs [8]. Especially, inositol therapy was demonstrated 
effective and beneficial to improve ovulation as a supplementation of clomiphene citrate $[9,10]$; it was reported there was no sufficient evidence to demonstrate the availability for the administration of myo-inositol in PCOS patients experiencing ovulation induction [11]. Moreover, hydrolaparoscopic ovarian drilling is a unique treatment for anovulatory women with PCOS, but this surgery causes tissue adhesion and other complications [12]. Therefore, due to such limitations, there is a need to identify an ideal treatment for PCOS.

Human mesenchymal stem cells (hMSCs) have become a research focus of clinical therapeutics owing to their properties of stemness, anti-inflammatory activity, the secretion of active factors, and differentiation into various types of somatic cells. MSCs can secrete numerous active factors such as vascular endothelial growth factor (VEGF), IL-10, and TNF- $\alpha$ [13-15] that are anti-inflammatory, angiogenic, and antifibrotic [15-17], which therefore can be helpful to impaired lungs, liver, kidney, endometrium, and ovary $[18,19]$. Moreover, MSCs can secrete estrogen, which, in consequence, may be potentially used as an effective treatment for patients with estrogen deficiency [20]. A previous study has demonstrated that MSCs administered to mice via tail vein injection had inhibited inflammation in PCOS [21].

Furthermore, MSCs improve the fertility of women with premature ovarian failure through intraovarian injection, which can minimize MSC diffusion to other tissues [22,23]. In particular, umbilical cord MSCs (UC-MSCs) entrapped in fibrin gels have been used in in vitro/in vivo construction of bone [24,25], cartilage [26], and the microvascular network [27]. Fibrin has been widely used as a desirable scaffold and carrier for MSCs, which can help MSCs reach the specific organ or tissue and subsequently decrease/stop bleeding after cell transplantation [28,29]. It has been used to construct artificial ovaries to preserve the fertility of a patient. In adults, fibrin clots can recruit hMSCs; however, the strong fibrinolytic activity of hMSCs plays a similar role as fibrin in matrix remodeling and wound healing [30]. This study aims to investigate whether intraovarian injection of UC-MSCs alone or within fibrin hydrogels can restore ovarian function in a PCOS rat model, to elucidate its underlying mechanism. This study also identifies therapeutic targets for assisted reproduction technology.

\section{Result}

\subsection{Fibrin Hydrogel Enhances UC-MSCs Growth}

The minimal phenotypic criteria for the cultured MSCs include positive expression of CD90, CD29, and CD105, and negative expression of HLA-DR, CD34, and CD45 [31]. Our results indicated that the UC-MSCs cultured in the study expressed CD90, CD29, and CD105, but not HLA-DR, CD34, or CD45 surface markers (Figure 1A). These results were confirmed by immunofluorescence histochemistry (Figure 1B). Moreover, MSCs have the ability to undergo extensive differentiation into multiple cell lineages such as cartilaginous and adipose cells (Figure 1C,D). 
A
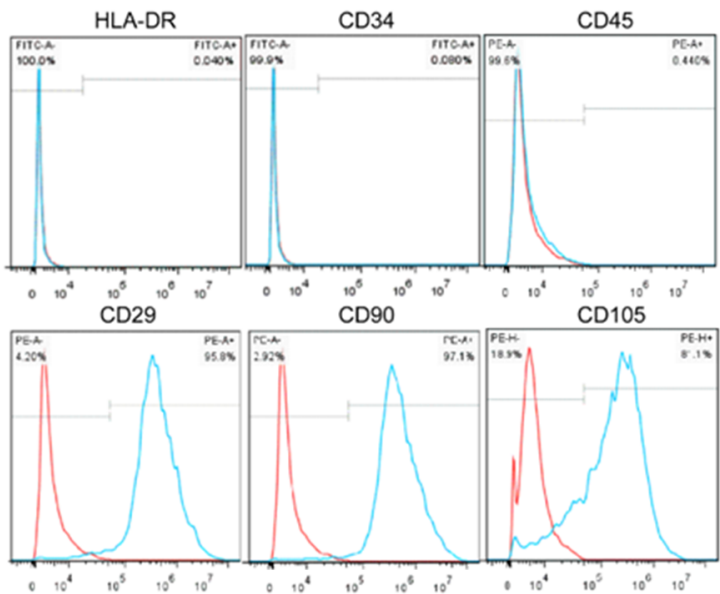

B

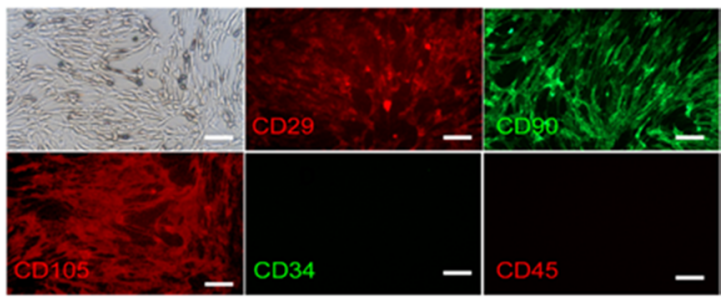

C D

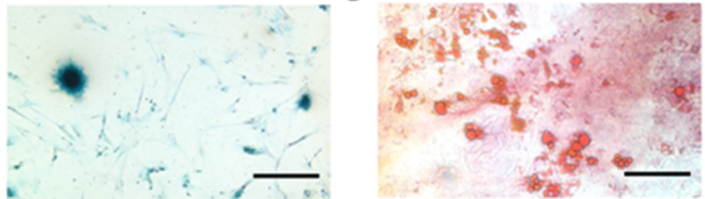

Figure 1. Characterization of umbilical cord mesenchymal stem cells (UC-MSCs). (A) Flow cytometry showing the percentage of cells expressing HLA-DR, CD-34, CD-45, CD90, CD29, and CD105. The cells also expressed CD90, CD29, and CD105, but not HLA-DR, CD34, or CD45. The red curve represents the blank, and the blue curve indicates positive expression. (B) UC-MSCs on glass slides were detected by fluorescence microscopy after hybridization with anti-CD antibodies (red: phycoreythrin (PE) label, green: fluorescein isothiocyanate (FITC) label). (C) Cartilage cells that differentiated from UC-MSCs were stained dark blue. (D) Adipocyte cells that differentiated from UC-MSCs were shown as red oil droplets.

The cross-linked fibrin formed the three-dimensional mesh for MSC encapsulation (Supplemental Figure S1). The UC-MSCs exhibited unfolding in a three-dimensional scaffold of fibrin and were tightly linked with fibrin fibers (Figure 2A, B right), but UC-MSCs on the surface of fibrin were similar with that on the culture dish, which was tightly arranged and had no more room to stretch out further (Figure 2B left). The proliferation efficiency of UC-MSCs inside the fibrin gel was higher than that on the surface of the fibrin gel (Figure 2C). 


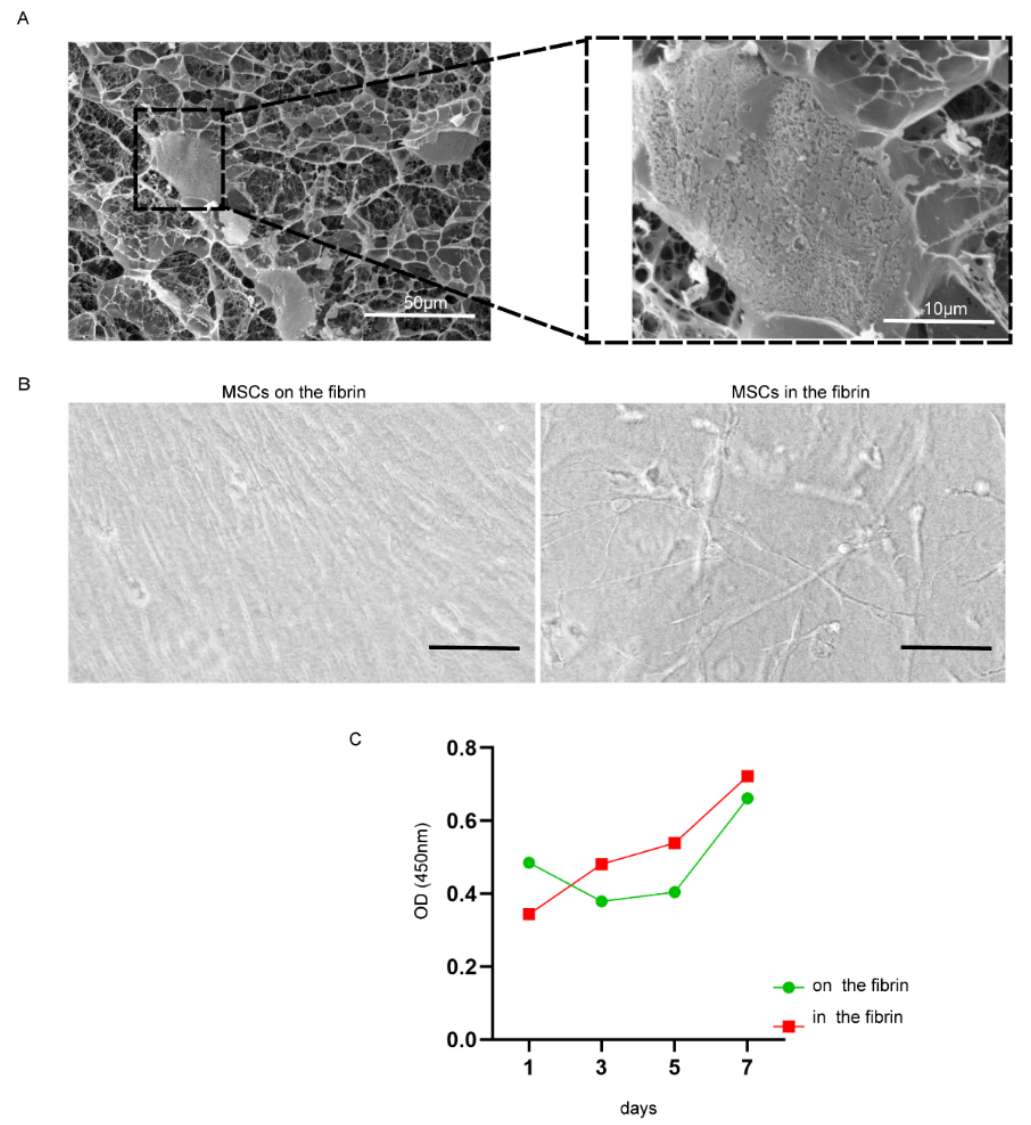

Figure 2. The status of growth and proliferation of UC-MSCs cultured with fibrin gel. (A) Frozen scanning electron micrographs. Right, magnified form of the cell indicated by black dotted bordered rectangle; magnification was 700 and 3000; scale bar, 50 and $10 \mu \mathrm{m}$. (B) Cells on (left) and inside (right) the fibrin gel captured by light microscopy (scale bar, $100 \mu \mathrm{m}$ ). (C) The cell proliferation was detected by CCK-8; the red curve represented cells cultured inside the fibrin gel, and the green curve represented cells cultured on the fibrin gel.

\subsection{Survival of UC-MSCs in Rat Ovaries and Estrous Cycles}

The survival duration of UC-MSCs in rat ovaries was assessed by detection of pre-labeling cells with luciferase on days 2, 5, and 7 of transplantation (Figure 3A). The decreasing expression levels of luciferase over time demonstrated a decrease in the number of UC-MSCs both in the UC-MSCs and UC-MSCs + fibrin groups. In contrast, no UC-MSCs were observed on the seventh day of implantation (Figure 3B).

Then, estrus cyclicity in rats was monitored by collecting vaginal smears (Figure 3C) at the beginning of the third day of transplantation. Compared with the estrus cyclicity of the normal group, there was no significant change observed in the other three groups during the first week after the implantation (Figure 3D). Normal estrous cyclicity was restored in the second week of transplantation in the UC-MSCs and UC-MSCs + fibrin groups, but diestrus was maintained in the PCOS group (Figure 3D). These findings indicated that normal functionality was restored within two weeks of UC-MSCs transplantation. 


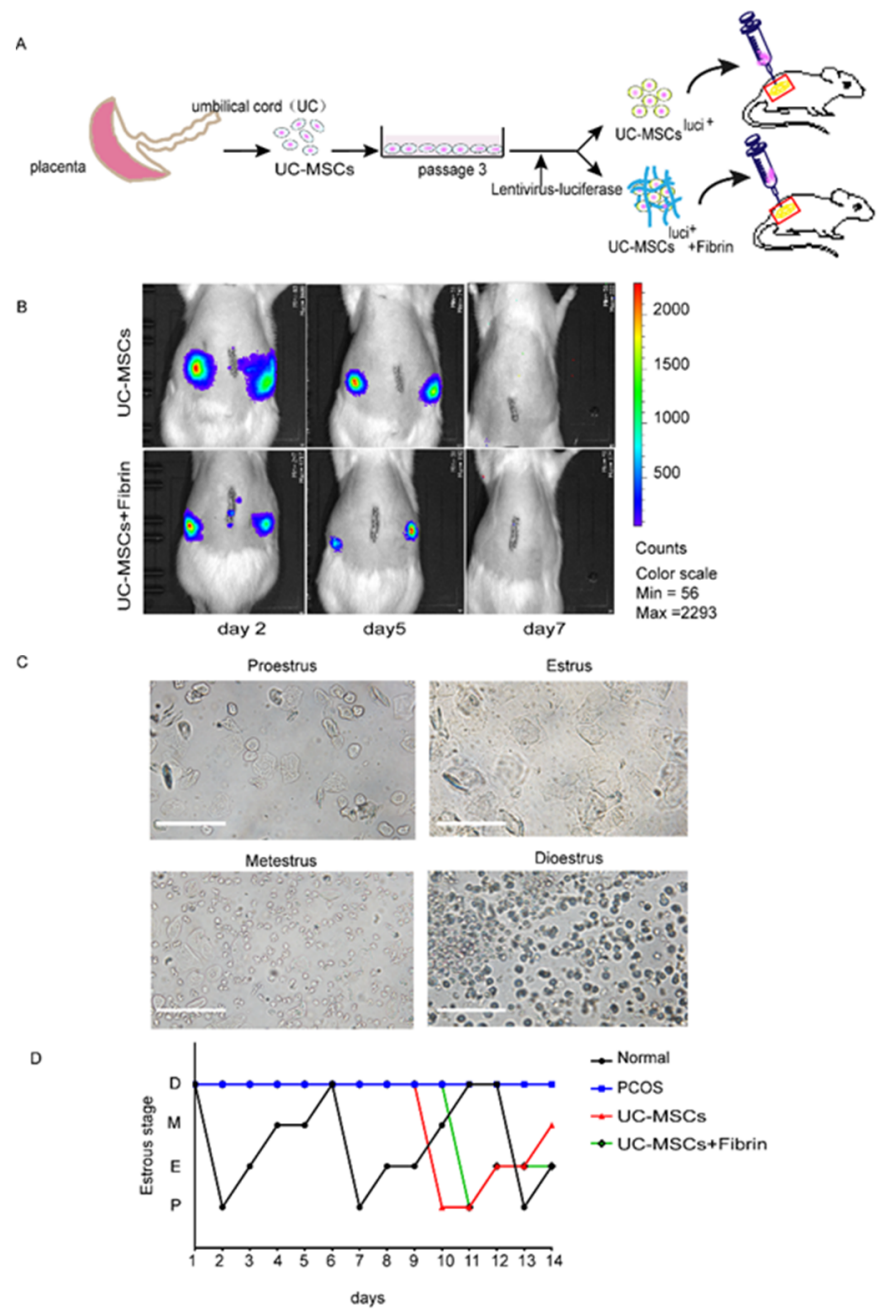

Figure 3. Experimental design and the comparison of estrous cyclicity in all groups. (A) Schematic illustrations of the transplantation experiments. UC-MSCs labeled with luciferase or embedded in the fibrin gel were directly injected into the ovaries (yellow circles outside the red square represents rat ovary). (B) The survival time of UC-MSCs with or without fibrin gel in the rat ovaries. The UC-MSCs in rats' ovaries were detected by IVIS lumina III on days 2, 5, and 7. (C) Estrus cycle was monitored by cytology of vaginal smears in four stages of the estrus cycle. Proestrus mostly showing epithelial cells; estrus, showing keratinocytes; metestrus showing epithelial cells, keratinocytes, and leukocytes; diestrus showing leukocytes. (D) The estrus cyclicity statistics. The estrus cycle of all groups was monitored two weeks after transplantation: black for the normal control group, blue for the polycystic ovarian syndrome (PCOS) model, red for the UC-MSCs group, and green for the UC-MSCs + fibrin group.

\subsection{UC-MSCs Enhance Ovary Size in PCOS Rats}

Our results demonstrated that the ovaries of PCOS rats were significantly smaller in size and weighed lighter than the normal rats (Figure 4A). Interestingly, UC-MSCs, as well as UC-MSCs + fibrin transplantation, enhanced ovary size and weight in PCOS rats within two weeks; however, it was not as large as that of the normal rats (Figure 4B,C). Moreover, UC-MSCs and UC-MSCs + fibrin administration increased the number of granulosa cells, whereas it reduced the number of immature cystic follicles in the ovary of PCOS rats (Figure 4D). Furthermore, UC-MSCs + fibrin increased the number of corpus luteum cells in the ovaries of PCOS rats. Among all four groups of rats, bodyweight had no significant difference (Figure 4C). Collectively, these results suggested that UC-MSCs can help restore the ovarian structure as well as cytology compared to normal ovaries. 


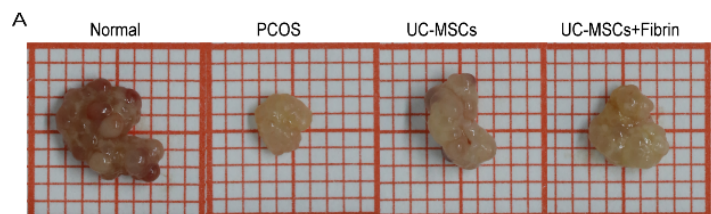

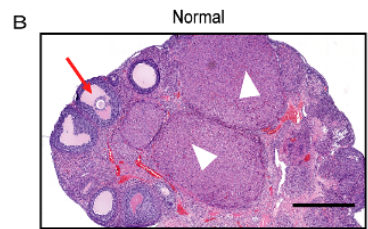

UC-MSCs

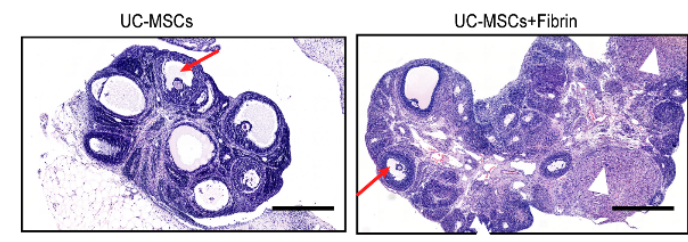

PCOS

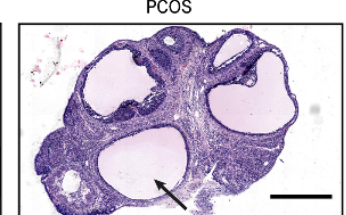

UC-MSCs+Fibri

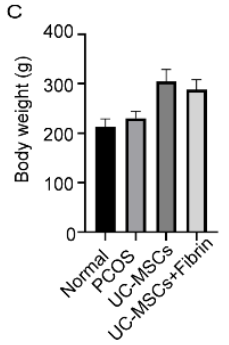

D

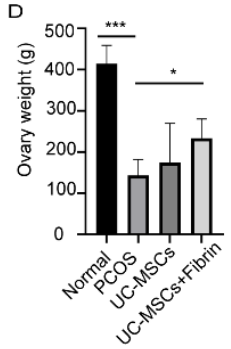

Figure 4. Comparison between ovary size and follicular morphology after implantation. (A) A representative ovary from various groups showing relative ovary size. (B) Ovarian and follicular morphology in various groups were examined by haematoxylin and eosin (H\&E) staining. Ovaries with thicker granular layer and a higher number of cells in the corpus luteum were assessed in the normal and UC-MSCs + fibrin group. Black arrow: cystic follicle with fewer granules, red arrow: follicle with more granules, white triangle: corpus luteum (scale bar, $500 \mu \mathrm{m}$ ). (C) Mean body weight did not significantly differ among all groups. (D) Ovary weight significantly differed between the PCOS and normal groups $\left({ }^{* * *} p<0.001\right)$ and between PCOS and UC-MSCs + fibrin groups $\left({ }^{*} p<0.5\right)$.

\subsection{Serum Hormone Levels}

Considerable variations in serum hormonal levels were observed after UC-MSCs and UC-MSCs mixed with fibrin were transplanted into the ovaries of PCOS rats. The PCOS rats showed significantly higher testosterone levels $(0.387 \pm 0.176 \mathrm{ng} / \mathrm{mL})$ compared to the normal group. UC-MSCs administration significantly reduced serum testosterone levels $(0.209 \pm 0.088 \mathrm{ng} / \mathrm{mL}$, $0.062 \pm 0.011 \mathrm{ng} / \mathrm{mL}, p<0.01$ ). However, UC-MSCs mixed with fibrin reduced testosterone levels to the levels observed in normal rats more efficiently, suggesting that UC-MSCs + fibrin administration may be potentially utilized in the treatment of hyperandrogenemia in PCOS patients. Furthermore, a significant difference in testosterone levels was observed between the UC-MSCs group and UC-MSCs + fibrin group $(p<0.01$, Figure 5D), revealing that UC-MSCs can restore androgen levels in PCOS more efficiently.

Significantly reduced concentrations of estradiol (E2) and progesterone were observed in the PCOS rat model compared to the control group as expected. UC-MSCs + fibrin treatment completely restored serum E2 levels in PCOS rats as observed in normal rats within two weeks (Figure 5A), whereas UC-MSCs alone also showed a significant increase in E2. However, treatment with UC-MSCs alone effectively restored progesterone levels to normal levels, whereas UC-MSCs + fibrin treatment increased mean progesterone levels $(p<0.000001)$ higher than the normal levels (Figure 5B). In PCOS rats, higher serum gonadotropin $(\mathrm{LH} / \mathrm{FSH})$ levels were observed compared to normal rats, whereas UC-MSCs with and without fibrin induced a reduction in serum gonadotropin levels to that in the control group (Figure 5C). These results collectively suggest that UC-MSCs with the fibrin scaffold had a greater impact on restoring hormonal dysfunction in the PCOS rat model. 

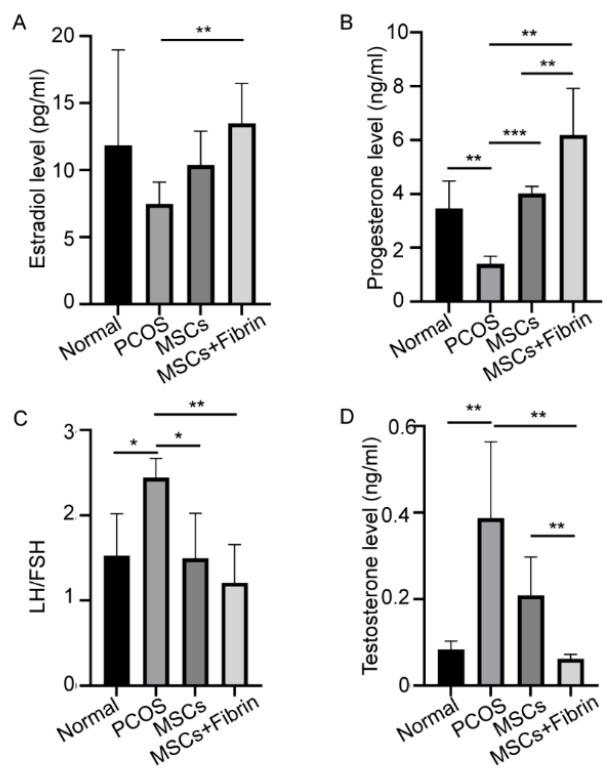

Figure 5. Treatment effect of UC-MSCs and UC-MSCs + fibrin on hormonal levels. (A) Levels of estradiol, (B) progesterone, (C) LH/FSH, and (D) testosterone $\left({ }^{*} p<0.5,{ }^{* *} p<0.01,{ }^{* * *} p<0.001\right)$.

\subsection{MSCs Restore TGF- $\beta 1$ Expression in PCOS Rats}

There is an increasing evidence that TGF- $\beta$ plays a critical role in the development of PCOS. Based on this concept, we investigated TGF- $\beta 1$ expression levels in our experimental groups by immunofluorescence staining. Notably higher TGF- $\beta 1$ expression levels were observed in PCOS rats compared to the other groups (Figure 6A). However, the UC-MSCs and UC-MSCs + fibrin treatments reduced TGF- $\beta 1$ expression levels comparable to the control rats after two weeks. To confirm this result, we further investigated TGF- $\beta 1$ RNA and protein expression levels in the study groups. As expected, UC-MSCs treatment restored TGF- $\beta 1$ RNA and protein expression levels comparable to the control group, suggesting that UC-MSCs can restore TGF- $\beta 1$ expression in PCOS rats (Figure 6B-D).
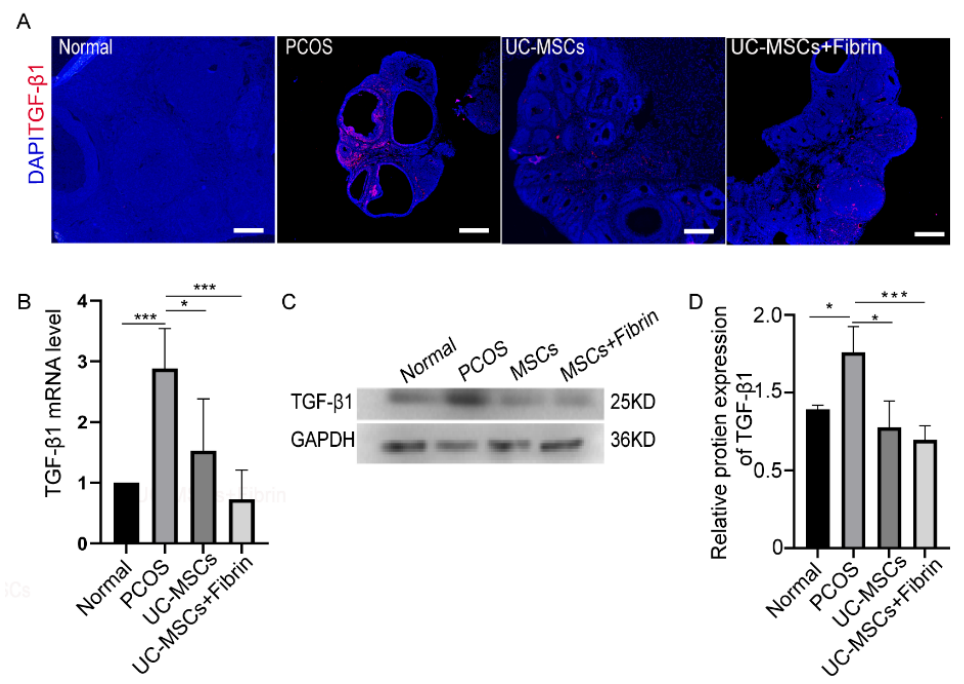

Figure 6. Immunohistochemical analysis and expression of transforming growth factor- $\beta 1$ (TGF- $\beta 1$ ). (A) Immunofluorescence analysis. TGF- $\beta 1$ expression was indicated in red and nuclei in blue color; scale bar, $100 \mu \mathrm{m}$. (B) The relative expression of TGF- $\beta 1$ RNA was quantified by RT-PCR. (C) TGF- $\beta 1$ protein was detected by western blotting. (D) Relative protein expression of TGF- $\beta 1$ was quantified by Image J 1.52a software and normalized to the GAPDH value. GAPDH was used as internal control $\left({ }^{*} p<0.5,{ }^{* *} p<0.01,{ }^{* * *} p<0.001\right)$. 


\section{Discussion}

The primary finding of this study is that UC-MSCs within fibrin hydrogel have shown therapeutic potential by restoring ovarian function and structure in PCOS rats. Our results reveal that direct injection of UC-MSCs alone as well as with fibrin scaffolds elevate serum estradiol and progesterone levels, whereas they significantly decrease gonadotropin (LH/FSH), testosterone, and TGF- $\beta 1$ levels. Furthermore, estrous cyclicity was restored, and the number of granulosa cells increased, while the number of immature cystic follicles in ovaries decreased in a PCOS rat model. The ovary size and weight significantly increased after intraovarian injection of UC-MSCs alone as well as UC-MSCs with fibrin. Thus, we infer that UC-MSCs can restore the function of damaged ovaries in PCOS rats. However, relatively few studies have examined the use of UC-MSCs combined with fibrin therapy to treat PCOS.

The survival time of administered UC-MSCs with the absence of fibrin scaffold in the host ovary was less than one week. No cells migrated to other tissues or organs, demonstrating that it is a risk-free therapeutic approach for PCOS; as previously reported, MSCs in fibrin hardly migrated independent of inflammatory factor and did not increase further on day 5 [32,33]. Depending on the severity of the disease, the accurate dose and optimal administration time must also be established. It is necessary to thoroughly understand the underlying mechanisms that regulate and modulate MSCs. What's more, appropriate methods should be developed. MSCs injection into the ovary under ultrasound guidance is safe and can serve as an effective approach for female patients without damaging or drifting to other tissues [34-36].

It is feasible for fibrin to supply three-dimensional supports and provide integrin-binding sites for MSCs [31], thus improving MSC adhesion and expansion [37], and allowing MSCs to secrete more bioactive factors to inhibit inflammation, reduce the apoptosis of granule cells, and promote angiogenesis [38]. Besides, fibrin is a common biomaterial in the fields of regenerative medicine and tissue engineering because of its ease of handling and quick preparation [33,39-41]. We illustrated that UC-MSCs enwrapped in fibrin can spread more extensively and exhibit higher proliferation rates than those on the surface of fibrin gels. The regenerative use of MSCs to recover ovarian function may thus potentially be applied for the treatment of PCOS. This is the first time that UC-MSCs with fibrin have been used to repair PCOS ovary through intraovarian injection, and the results demonstrated that fibrin facilitated UC-MSCs in repairing PCOS ovaries.

Women with PCOS have characteristic neuroendocrine abnormalities, including persistently elevated GnRH pulse frequency [42] and increased production of gonadotropins [43], which lead to abnormal cyclicity [44,45] and reduced progesterone levels [45]. Estrogen plays a permissive role in progesterone suppression of GnRH pulse frequency [46]. Hyperandrogenemia is another positive feedback to gonadotropin production, and UC-MSCs reduce androgen levels. It provides promising insight into the hormonal regulation of expression in PCOS patients. However, the mechanism by which MSC transplantation promotes normal reproductive hormonal concentrations and hence ovarian function requires further investigation.

The application of UC-MSCs in rat models of ovarian dysfunction has been previously reported with positive effects on damaged ovary tissues such as increased E2 levels and anti-inflammatory effects [47]. Additionally, MSCs helped restore ovarian function by downregulating proinflammatory cytokines [47]. PCOS rats showed improved ovarian fibrosis with a TGF- $\beta 1$ receptor inhibitor [48]. After MSCs navigated to damaged sites, they interacted closely with local stimuli such as cytokines [49]. TGF- $\beta 1$ is a crucial factor of fibrosis, which activates the TGF- $\beta 1 /$ SMAD signal pathway and induces more deposition of the extracellular matrix leading to fibrosis [15-17]. Increased TGF- $\beta 1$ expression in ovaries induces granulosa cell apoptosis and ovarian fibrosis in PCOS models $[7,50]$. The results of our study demonstrate that relative RNA and protein expression levels of TGF- $\beta 1$ dramatically decreased after UC-MSCs were transplanted within fibrin, which may facilitate UC-MSCs to diminish TGF- $\beta 1$ levels. Furthermore, we reveal that UC-MSCs administration with or without fibrin raises the healthy follicles and hence restores the normal gonadotropin levels in the PCOS rat model within two weeks. 
In this study, we took advantage of multiple characteristics, such as three-dimensional scaffold, porosity, syringeability, and hemostasis of fibrin gels [51,52] as well as abilities of anti-inflammation, repair, etc., Ref. [53] of MSCs in repairing PCOS ovaries. We preliminarily carried on the research of the feasibility of UC-MSCs combined with fibrin repairing of PCOS ovary. This is a convenient and highly efficient approach compared with other methods. However, the mechanism and possible risks are still not clear, which need to be explored further in the future. Ultimately, the present body of work represents a principal methodology to enhance tissue function, which would be conducive for pharmaceuticals development and regenerative medicine with further refinement.

\section{Methods and Materials}

\subsection{Ethics}

All animal experiments were approved by the Institutional Animal Care and Use Committee (IACUC) of the Institute of Zoology (Ethical approval No. IOZ20170078), Chinese Academy of Sciences, in accordance with institutional and national guidelines. The 21-day-old female rats were purchased from SPF Biotechnology Co., Ltd. (Beijing, China) and were provided with food and water ad libitum, $12 \mathrm{~h} \mathrm{light} / 12 \mathrm{~h}$ dark at $24^{\circ} \mathrm{C}$ and room temperature until euthanasia after two weeks of transplantation.

\subsection{UC-MSCs Culture and Identification}

The UC-MSCs used in this study were the second-generation human umbilical cord cells that were granted as a gift by Chongqing Sidemu Biotechnology Co., Ltd. These cells were cultured and passaged; at the third passage, the UC-MSCs were digested and dissociated to single cells, then incubated with $\mathrm{AB}$ human serum for 5 mins, and interacted with fluorescein isothiocyanate (FITC) or phycoreythrin (PE)-conjugated antibodies, i.e., mouse antihuman antibodies (CD34, CD45, CD90, CD29, CD105, HLA-DR, Santa Cruz Biotechnology, Inc.) for $1 \mathrm{~h}$ in the dark; then, cell flow analysis of cell surface markers was performed. UC-MSCs were cultured in a special differentiation culture medium (Gibco, Co., Ltd.) for 14 to 21 days, then cartilage cells were stained with Alcian blue, and adipose cells with Oil red, and then observed with a Nikon microscope.

\subsection{Coculturing UC-MSCs in Fibrin Gels}

Fibrin gels were composed of $10 \mathrm{mg} / \mathrm{mL}$ fibrinogen and $5 \mathrm{U} / \mathrm{mL}$ thrombin (1:1), dissolved in PBS. Approximately $200 \mu \mathrm{L}$ of the fibrin gel were placed into each well of a 12-well plate, incubated with $5 \%$ $\mathrm{CO}_{2}$ for 40 mins at $37^{\circ} \mathrm{C}$, and then UC-MSCs $\left(5 \times 10^{4}\right)$ were cultured on the surface of the fibrin gel of each well. In another group, UC-MSCs $\left(5 \times 10^{4}\right)$ were mixed with the fibrin gel, placed into each well of the 12-well plates, and incubated for 40 mins, and then the culture medium was added [37]. On days 1,3,5, and 7, the UC-MSCs from three random wells from each group were digested with $50 \mathrm{FU} / \mathrm{mL}$ nattokinase for $40 \mathrm{mins}$ at $37^{\circ} \mathrm{C}$, washed with PBS, centrifuged, resuspended, and cultured with the CCK-8 agent for $1 \mathrm{~h}$ at $37^{\circ} \mathrm{C}$. Then, the OD was measured using an automatic microplate reader and analyzed.

\subsection{Scanning Electron Microscopy}

Approximately $1 \times 10^{6}$ UC-MSCs were mixed with $100 \mu \mathrm{L}$ of fibrin gel mentioned above in a spherical mold and polymerized for $40 \mathrm{mins}$ at $37^{\circ} \mathrm{C}$. Then, the mold was gently collected and placed into a plate with culture medium supplemented with aprotinin $250 \mathrm{U} / \mathrm{mL}$, while avoiding the gel balls to adhere to the bottom of the plate. After three days, the gel balls were washed with PBS thrice and observed under a scanning electron microscope (Hitachi S-3000N, Institute of Genetics and Developmental Biology, Chinese Academy of Sciences). 


\subsection{In Vivo Experimental Design}

A group of 21-day-old female rats $(n=15)$ was injected with testosterone propionate $(10 \mathrm{mg} / \mathrm{kg}$ body weight) continuously for 35 days, whereas another group $(n=5)$ was injected with the same dose of sesame oil and designated as the control group. After 35 days, the estrous period of the rats was detected by observing the vaginal smears under a light microscope without staining [54]. The rats that remained in the diestrum were designated as a model for PCOS, and were further divided into three groups, including the PCOS group $(n=5)$, UC-MSCs group after intraovarian injection of UC-MSCs $\left(1 \times 10^{6}\right.$ before 5th passage) labeled with luciferase $(n=5)$, and UC-MSCs + fibrin group after intraovarian injection of UC-MSCs mixed with fibrin $(10 \mathrm{mg} / \mathrm{mL}$ fibrinogen and $2.5 \mathrm{U} / \mathrm{mL}$ thrombin, $1: 1 \mathrm{v} / \mathrm{v})(\mathrm{n}=5)$. All intraovarian injections were performed with the animals under anesthesia using isoflurane inhalation in a rodent anesthesia vaporizer (Shanghai Yuyan Instruments Co., Ltd.). All rats continued to be raised with sufficient water and food and at the appropriate room temperature. After three days of transplantation, vaginal smears were observed each day under the light microscope until day 14.

To investigate the survival time of UC-MSCs in the ovary, three random rats from each group were injected with D-luciferin, sodium salt $(150 \mathrm{mg} / \mathrm{kg}$, Yeasen Co., Ltd.) intraperitoneally and detected via IVIS lumina III (Institute of Biophysics, Chinese Academy of Science) at 2, 5, and 7 days of transplantation.

After 14 days of transplantation, blood was collected from all groups by cardiac puncture, centrifuged for 20 mins at $4000 \mathrm{rpm}$, and serum preserved at $-80{ }^{\circ} \mathrm{C}$ was used to measure serum hormone levels. Before blood collection, the rats were anesthetized with isoflurane, and body weights were recorded. Subsequently, all rats were euthanized by cervical dislocation, and ovaries were dissected and weighed; one ovary of each animal was preserved at $-80{ }^{\circ} \mathrm{C}$ for RNA and protein extraction, and the other was fixed in Bouin's fluid at $4{ }^{\circ} \mathrm{C}$.

\subsection{Hormonal Assay}

All serum samples were detected by the Beijing North Institute of Biotechnology Co., Ltd. The data were analyzed using GraphPad Prism 8.0.2 (Graph Pad Software Inc., San Diego, CA, USA).

\subsection{Histological Analysis}

The fixed ovaries were embedded with paraffin, $5 \mu \mathrm{m}$ serial sections were prepared, and some were randomly stained with haematoxylin and eosin and captured using Leica Aperio VESA8 (Germany). The remaining sections were treated with antimouse TGF- $\beta 1$ antibody (Santa Cruz Biotechnology), then observed under a super-resolution confocal microscope (Ti-E A1R-STORM, Nikon, Japan).

\subsection{Quantitative Real-Time PCR (QRT-PCR)}

Total RNA was isolated from half of each ovary, preserved at $-80{ }^{\circ} \mathrm{C}$ using TRIzol according to the manufacturer's protocol, purified with DNase, and quantified using a NanoDrop 2000 spectrophotometer (Thermo Fisher Scientific). cDNA was synthesized using 5X All-In-One RT MasterMix (Applied Biological Materials, Inc.) according to the manufacturer's protocol. qPCR was performed on the CFX96 Touch Real-Time PCR Detection System (Bio-Rad) using the TGF- $\beta 1$ primers (Forward: 5'-GGCCAGAT CCTGTCCAAGC-3'; Reverse: 5'-GTGGGTTTCCACCATTAGCAC-3'), and the GAPDH primers (Forward: 5'-ATGGCACAGTCAAGGCTGAGA-3'; Reverse: 5'-CGCTCCT GGAAGATGGTGAT-3') [55]. The other half tissue of ovary from each group was homogenized in the lysis buffer (Beyotime) using tissue homogenizer, centrifuged for 30 mins at $4{ }^{\circ} \mathrm{C}$, and protein was extracted from the supernatant; protein levels were measured by using Bio-Rad protein assay or Bio-Rad ChemiDoc system. 


\subsection{Statistical Analysis}

All data are presented as the mean \pm SEM of at least three independent experiments. Multiple $t$-tests by the software of GraphPad Prism 8.0.2 was used for comparison of groups, and differences were considered statistically significant at ${ }^{*} p<0.05$.

Supplementary Materials: The following are available online at http://www.mdpi.com/2076-3417/10/10/3598/s1.

Author Contributions: Conceptualization, Y.L. (Yixun Liu) and Q.G.; methodology, Y.L. (Yixun Liu) and Q.G.; validation, Y.L. (Yixun Liu) and Q.G.; formal analysis, Y.L. (Yuanyuan Li); investigation, Y.L. (Yuanyuan Li) and J.G.; resources, S.D. and Z.G.; data curation, Y.L. (Yuanyuan Li) and Q.G.; writing-original draft preparation, Y.L. (Yuanyuan Li); writing, review and editing, Y.L. (Yixun Liu) and Q.G.; visualization, Y.L. (Yixun Liu); supervision, Q.G.; project administration, Y.L. (Yixun Liu) and Q.G; All authors have read and agreed to the published version of the manuscript.

Funding: This research was funded by the Strategic Priority Research Program of the Chinese Academy of Sciences, Grant No. XDA16020802 and CAS Pioneer Hundred Talents Program, Y829F11102. And the APC was funded by XDA16020802.

Conflicts of Interest: The authors declare no conflict of interest.

\section{References}

1. Sheng, Y.; Lu, G.; Liu, J.; Liang, X.; Ma, Y.; Zhang, X.; Zhang, S.; Sun, Y.; Sun, Y.; Chen, W.; et al. Effect of body mass index on the outcomes of controlled ovarian hyperstimulation in Chinese women with polycystic ovary syndrome: A multicenter, prospective, observational study. J. Assist. Reprod. Genet. 2017, 34, 61-70. [CrossRef] [PubMed]

2. Jayasena, C.N.; Franks, S. The management of patients with polycystic ovary syndrome. Nat. Rev. Endocrinol. 2014, 10, 624-636. [CrossRef] [PubMed]

3. Artini, P.G.; Obino, M.E.R.; Sergiampietri, C.; Pinelli, S.; Papini, F.; Casarosa, E.; Cela, V. PCOS and pregnancy: A review of available therapies to improve the outcome of pregnancy in women with polycystic ovary syndrome. Expert Rev. Endocrinol. Metab. 2018, 13, 87-98. [CrossRef] [PubMed]

4. Franks, S. Polycystic Ovary Syndrome. N. Engl. J. Med. 1995, 333, 853-861. [CrossRef] [PubMed]

5. Wu, X.Q.; Wang, Y.Q.; Xu, S.M.; Liu, J.F.; Bi, X.Y.; Wang, Z.Q.; Zhang, J.P. The WNT/beta-catenin signaling pathway may be involved in granulosa cell apoptosis from patients with PCOS in North China. J. Gynecol. Obs. Hum. Reprod. 2017, 46, 93-99. [CrossRef] [PubMed]

6. Asselin, E.; Xiao, C.W.; Wang, Y.F.; Tsang, B.K. Mammalian follicular development and atresia: Role of apoptosis. Biol. Signals Recept. 2000, 9, 87-95. [CrossRef]

7. Zhang, X.; Zhang, C.; Shen, S.; Xia, Y.; Yi, L.; Gao, Q.; Wang, Y. Dehydroepiandrosterone induces ovarian and uterine hyperfibrosis in female rats. Hum. Reprod. (Oxford, England) 2013, 28, 3074-3085. [CrossRef]

8. Escobar-Morreale, H.F. Polycystic ovary syndrome: Definition, aetiology, diagnosis and treatment. Nat. Rev. Endocrinol. 2018, 14, 270. [CrossRef]

9. Laganà, A.S.; Rossetti, P.; Sapia, F.; Chiofalo, B.; Buscema, M.; Valenti, G.; Rapisarda, A.M.C.; Vitale, S.G. Evidence-Based and Patient-Oriented Inositol Treatment in Polycystic Ovary Syndrome: Changing the Perspective of the Disease. Int. J. Endocrinol. Metab. 2017, 15, e43695. [CrossRef]

10. Facchinetti, F.; Appetecchia, M.; Aragona, C.; Bevilacqua, A.; Bezerra Espinola, M.S.; Bizzarri, M.; D’Anna, R.; Dewailly, D.; Diamanti-Kandarakis, E.; Hernández Marín, I.; et al. Experts' opinion on inositols in treating polycystic ovary syndrome and non-insulin dependent diabetes mellitus: A further help for human reproduction and beyond. Expert Opin. Drug Metab. Toxicol. 2020, 16, 255-274. [CrossRef]

11. Showell, M.G.; Mackenzie-Proctor, R.; Jordan, V.; Hodgson, R.; Farquhar, C. Inositol for subfertile women with polycystic ovary syndrome. Cochrane Database Syst. Rev. 2018, 12, Cd012378. [CrossRef] [PubMed]

12. Casa, A.; Sesti, F.; Marziali, M.; Gulemi, L.; Piccione, E. Transvaginal hydrolaparoscopic ovarian drilling using bipolar electrosurgery to treat anovulatory women with polycystic ovary syndrome. J. Am. Assoc. Gynecol. Laparosc. 2003, 10, 219-222. [CrossRef]

13. Shojafar, E.; Mehranjani, M.S.; Shariatzadeh, S.M.A. Adipose derived mesenchymal stem cells improve the structure and function of autografted mice ovaries through reducing oxidative stress and inflammation: A stereological and biochemical analysis. Tissue Cell. 2019, 56, 23-30. [CrossRef] [PubMed] 
14. Yoon, S.Y. Mesenchymal stem cells for restoration of ovarian function. Clin. Exp. Reprod. Med. 2019, 46, 1-7. [CrossRef] [PubMed]

15. Nombela-Arrieta, C.; Ritz, J.; Silberstein, L.E. The elusive nature and function of mesenchymal stem cells. Nat. Rev. Mol. Cell Biol. 2011, 12, 126-131. [CrossRef]

16. Yuan, K.; Lai, C.Y.; Wei, L.L.; Feng, T.H.; Yang, Q.Y.; Zhang, T.Y.; Lan, T.; Yao, Y.T.; Xiang, G.M.; Huang, X.L. The Effect of Vascular Endothelial Growth Factor on Bone Marrow Mesenchymal Stem Cell Engraftment in Rat Fibrotic Liver upon Transplantation. Stem Cells Int. 2019, 2019, 13. [CrossRef]

17. Caretti, A.; Peli, V.; Colombo, M.; Zulueta, A. Lights and Shadows in the Use of Mesenchymal Stem Cells in Lung Inflammation, a Poorly Investigated Topic in Cystic Fibrosis. Cells 2019, 9, 20. [CrossRef]

18. Bagno, L.; Hatzistergos, K.E.; Balkan, W.; Hare, J.M. Mesenchymal Stem Cell-Based Therapy for Cardiovascular Disease: Progress and Challenges. Mol. Ther. 2018, 26, 1610-1623. [CrossRef]

19. Han, C.; Zhou, J.; Liang, C.; Liu, B.; Pan, X.; Zhang, Y.; Wang, Y.; Yan, B.; Xie, W.; Liu, F.; et al. Human umbilical cord mesenchymal stem cell derived exosomes encapsulated in functional peptide hydrogels promote cardiac repair. Biomater. Sci. 2019, 7, 2920-2933. [CrossRef]

20. Li, J.; Peng, X.; Zeng, X.; Liu, B.; Hao, Q.; Yu, X.; Zhu, L.; Hu, Q. Estrogen Secreted by Mesenchymal Stem Cells Necessarily Determines Their Feasibility of Therapeutical Application. Sci Rep. 2015, 5, 15286. [CrossRef]

21. Xie, Q.; Xiong, X.L.; Xiao, N.; He, K.; Chen, M.S.; Peng, J.; Su, X.; Mei, H.; Dai, Y.N.; Wei, D.; et al. Mesenchymal Stem Cells Alleviate DHEA-Induced Polycystic Ovary Syndrome (PCOS) by Inhibiting Inflammation in Mice. Stem Cells Int. 2019, 2019, 12. [CrossRef] [PubMed]

22. Ding, L.; Yan, G.; Wang, B.; Xu, L.; Gu, Y.; Ru, T.; Cui, X.; Lei, L.; Liu, J.; Sheng, X.; et al. Transplantation of UC-MSCs on collagen scaffold activates follicles in dormant ovaries of POF patients with long history of infertility. Sci. China Life Sci. 2018, 61, 1554-1565. [CrossRef] [PubMed]

23. Terraciano, P.; Garcez, T.; Ayres, L.; Durli, I.; Baggio, M.; Kuhl, C.P.; Laurino, C.; Passos, E.; Paz, A.H.; Cirne-Lima, E. Cell therapy for chemically induced ovarian failure in mice. Stem Cells Int. 2014, 2014, 720753. [CrossRef] [PubMed]

24. Murphy, K.C.; Hughbanks, M.L.; Binder, B.Y.; Vissers, C.B.; Leach, J.K. Engineered Fibrin Gels for Parallel Stimulation of Mesenchymal Stem Cell Proangiogenic and Osteogenic Potential. Ann. Biomed. Eng. 2015, 43, 2010-2021. [CrossRef] [PubMed]

25. Murphy, K.C.; Fang, S.Y.; Leach, J.K. Human mesenchymal stem cell spheroids in fibrin hydrogels exhibit improved cell survival and potential for bone healing. Cell Tissue Res. 2014, 357, 91-99. [CrossRef]

26. Commins, J.; Irwin, R.; Matuska, A.; Goodale, M.; Delco, M.; Fortier, L. Biological Mechanisms for Cartilage Repair Using a BioCartilage Scaffold: Cellular Adhesion/Migration and Bioactive Proteins. Cartilage 2020, 1947603519900803. [CrossRef]

27. Rambol, M.H.; Han, E.; Niklason, L.E. Microvessel Network Formation and Interactions with Pancreatic Islets in Three-Dimensional Chip Cultures. Tissue Eng. Part A 2020. [CrossRef]

28. Janmey, P.A.; Winer, J.P.; Weisel, J.W. Fibrin gels and their clinical and bioengineering applications. J. R. Soc. Interface 2009, 6, 1-10. [CrossRef]

29. Whelan, D.; Caplice, N.M.; Clover, A.J.P. Fibrin as a delivery system in wound healing tissue engineering applications. J. Control. Release 2014, 196,1-8. [CrossRef]

30. Neuss, S.; Schneider, R.K.; Tietze, L.; Knuchel, R.; Jahnen-Dechent, W. Secretion of fibrinolytic enzymes facilitates human mesenchymal stem cell invasion into fibrin clots. Cells Tissues Organs 2010, 191, 36-46. [CrossRef]

31. Tobita, M.; Tajima, S.; Mizuno, H. Adipose tissue-derived mesenchymal stem cells and platelet-rich plasma: Stem cell transplantation methods that enhance stemness. Stem Cell. Res. Ther. 2015, 6, 215. [CrossRef] [PubMed]

32. Wang, X.; Chen, H.; Zeng, X.; Guo, W.; Jin, Y.; Wang, S.; Tian, R.; Han, Y.; Guo, L.; Han, J.; et al. Efficient lung cancer-targeted drug delivery via a nanoparticle/MSC system. Acta Pharm. Sin. B 2019, 9, 167-176. [CrossRef] [PubMed]

33. Kim, I.; Lee, S.K.; Yoon, J.I.; Kim, D.E.; Kim, M.; Ha, H. Fibrin glue improves the therapeutic effect of MSCs by sustaining survival and paracrine function. Tissue Eng. Part A 2013, 19, 2373-2381. [CrossRef] [PubMed]

34. Mitra, S.; Nayak, P.K.; Agrawal, S. Laparoscopic ovarian drilling: An alternative but not the ultimate in the management of polycystic ovary syndrome. J. Nat. Sci. Biol. Med. 2015, 6, 40-48. 
35. Grady, S.T.; Watts, A.E.; Thompson, J.A.; Penedo, M.C.T.; Konganti, K.; Hinrichs, K. Effect of intra-ovarian injection of mesenchymal stem cells in aged mares. J. Assist. Reprod. Genet. 2019, 36, 543-556. [CrossRef]

36. Ferraretti, A.P.; Gianaroli, L.; Magli, M.C.; Iammarrone, E.; Feliciani, E.; Fortini, D. Transvaginal ovarian drilling: A new surgical treatment for improving the clinical outcome of assisted reproductive technologies in patients with polycystic ovary syndrome. Fertil. Steril. 2001, 76, 812-816. [CrossRef]

37. Goetzke, R.; Keijdener, H.; Franzen, J.; Ostrowska, A.; Nuchtern, S.; Mela, P.; Wagner, W. Differentiation of Induced Pluripotent Stem Cells towards Mesenchymal Stromal Cells is Hampered by Culture in 3D Hydrogels. Sci. Rep. 2019, 9, 15578. [CrossRef]

38. Murphy, K.C.; Whitehead, J.; Zhou, D.; Ho, S.S.; Leach, J.K. Engineering fibrin hydrogels to promote the wound healing potential of mesenchymal stem cell spheroids. Acta Biomater. 2017, 64, 176-186. [CrossRef]

39. Weisel, J.W.; Litvinov, R.I. Fibrin Formation, Structure and Properties. In Fibrous Proteins: Structures and Mechanisms; Parry, D.A.D., Squire, J.M., Eds.; Springer International Publishing: Cham, Switzerland, 2017; pp. 405-456.

40. Roura, S.; Gálvez-Montón, C.; Bayes-Genis, A. Fibrin, the preferred scaffold for cell transplantation after myocardial infarction? An old molecule with a new life. J. Tissue Eng. Regen. Med. 2017, 11, $2304-2313$. [CrossRef]

41. Mazlyzam, A.L.; Aminuddin, B.S.; Fuzina, N.H.; Norhayati, M.M.; Fauziah, O.; Isa, M.R.; Saim, L.; Ruszymah, B.H.I. Reconstruction of living bilayer human skin equivalent utilizing human fibrin as a scaffold. Burns 2007, 33, 355-363. [CrossRef]

42. Waldstreicher, J.; Santoro, N.F.; Hall, J.E.; Filicori, M.; Crowley, W.F., Jr. Hyperfunction of the hypothalamic-pituitary axis in women with polycystic ovarian disease: Indirect evidence for partial gonadotroph desensitization. J. Clin. Endocrinol. Metab. 1988, 66, 165-172. [CrossRef] [PubMed]

43. Taylor, A.E.; McCourt, B.; Martin, K.A.; Anderson, E.J.; Adams, J.M.; Schoenfeld, D.; Hall, J.E. Determinants of abnormal gonadotropin secretion in clinically defined women with polycystic ovary syndrome. J. Clin. Endocrinol. Metab. 1997, 82, 2248-2256. [CrossRef]

44. Filicori, M.; Santoro, N.; Merriam, G.R.; Crowley, W.F., Jr. Characterization of the physiological pattern of episodic gonadotropin secretion throughout the human menstrual cycle. J. Clin. Endocrinol. Metab. 1986, 62, 1136-1144. [CrossRef] [PubMed]

45. Rossmanith, W.G.; Liu, C.H.; Laughlin, G.A.; Mortola, J.F.; Suh, B.Y.; Yen, S.S. Relative changes in LH pulsatility during the menstrual cycle: Using data from hypogonadal women as a reference point. Clin. Endocrinol. (Oxf.) 1990, 32, 647-660. [CrossRef] [PubMed]

46. Nippoldt, T.B.; Reame, N.E.; Kelch, R.P.; Marshall, J.C. The roles of estradiol and progesterone in decreasing luteinizing hormone pulse frequency in the luteal phase of the menstrual cycle. J. Clin. Endocrinol. Metab. 1989, 69, 67-76. [CrossRef] [PubMed]

47. Kim, T.H.; Choi, J.H.; Jun, Y.; Lim, S.M.; Park, S.; Paek, J.Y.; Lee, S.H.; Hwang, J.Y.; Kim, G.J. 3D-cultured human placenta-derived mesenchymal stem cell spheroids enhance ovary function by inducing folliculogenesis. Sci. Rep. 2018, 8, 15313. [CrossRef] [PubMed]

48. Wang, D.; Wang, W.; Liang, Q.; He, X.; Xia, Y.; Shen, S.; Wang, H.; Gao, Q.; Wang, Y. DHEA-induced ovarian hyperfibrosis is mediated by TGF-beta signaling pathway. J. Ovarian Res. 2018, 11, 6. [CrossRef]

49. Edessy, M.; Hosni, H.N.; Shady, Y.; Waf, Y.; Bakr, S.; Kamel, M. Autologous stem cells therapy, the first baby of idiopathic premature ovarian failure. Acta Med. Int. 2016, 3, 19. [CrossRef]

50. Takahashi, N.; Harada, M.; Hirota, Y.; Nose, E.; Azhary, J.M.; Koike, H.; Kunitomi, C.; Yoshino, O.; Izumi, G.; Hirata, T.; et al. Activation of Endoplasmic Reticulum Stress in Granulosa Cells from Patients with Polycystic Ovary Syndrome Contributes to Ovarian Fibrosis. Sci. Rep. 2017, 7, 13. [CrossRef]

51. Weisel, J.W.; Litvinov, R.I. Fibrin Formation, Structure and Properties. Subcell. Biochem. 2017, 82, 405-456.

52. Ahmed, T.A.; Dare, E.V.; Hincke, M. Fibrin: A versatile scaffold for tissue engineering applications. Tissue Eng. Part B Rev. 2008, 14, 199-215. [CrossRef] [PubMed]

53. Jimenez-Puerta, G.J.; Marchal, J.A.; López-Ruiz, E.; Gálvez-Martín, P. Role of Mesenchymal Stromal Cells as Therapeutic Agents: Potential Mechanisms of Action and Implications in Their Clinical Use. J. Clin. Med. 2020, 9, 445. [CrossRef] [PubMed] 
54. Chaudhari, N.K.; Nampoothiri, L.P. Neurotransmitter alteration in a testosterone propionate-induced polycystic ovarian syndrome rat model. Horm. Mol. Biol. Clin. Investig. 2017, 29, 71-77. [CrossRef] [PubMed]

55. Zhang, C.Y.; Zhou, G.C.; Chen, Y.Z.; Liu, S.Z.; Chen, F.; Xie, L.C.; Wang, W.; Zhang, Y.G.; Wang, T.Y.; Lai, X.L.; et al. Human umbilical cord mesenchymal stem cells alleviate interstitial fibrosis and cardiac dysfunction in a dilated cardiomyopathy rat model by inhibiting TNF- and TGF-1/ERK1/2 signaling pathways. Mol. Med. Rep. 2018, 17, 71-78. [CrossRef] [PubMed]

(C) 2020 by the authors. Licensee MDPI, Basel, Switzerland. This article is an open access article distributed under the terms and conditions of the Creative Commons Attribution (CC BY) license (http://creativecommons.org/licenses/by/4.0/). 